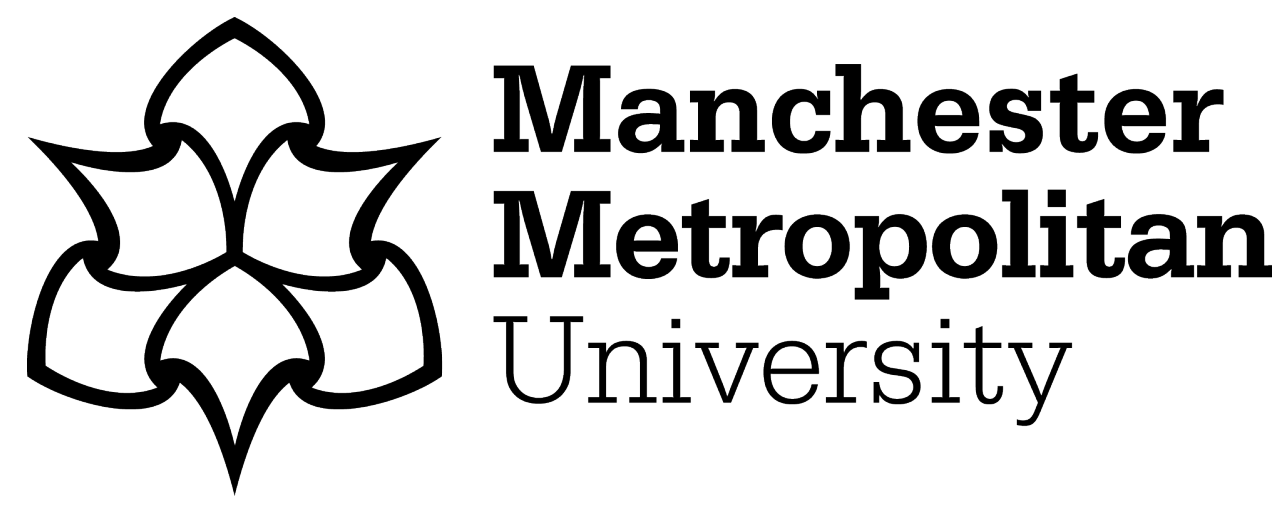

Witham, Gary and Haigh, C (2018) A narrative literature review examining cancer treatment issues for patients living with intellectual disabilities. European Journal of Oncology Nursing, 36. pp. 9-15. ISSN 1532-2122

Downloaded from: https://e-space.mmu.ac.uk/621157/

Version: Accepted Version

Publisher: Elsevier

DOI: https://doi.org/10.1016/j.ejon.2018.07.004

Usage rights: Creative Commons: Attribution-Noncommercial-No Derivative Works 4.0

Please cite the published version 


\title{
A narrative literature review examining cancer treatment issues for patients living with intellectual disabilities.
}

\begin{abstract}
Purpose: The experiences of cancer care can be mediated by many different factors and this narrative literature review aims to explore the experiences of cancer care in relation to people with intellectual disabilities receiving cancer treatment.

Method: We undertook a search for articles in English from (Jan) 2000-(Feb) 2018 using Medline, CINAHL, ScienceDirect, ASSIA and Wiley. The inclusion criteria are 2000-2018, English language and focussing on experiences of cancer journey. We used a narrative approach and thematic analysed the data.

Results: There were 10 papers that met our inclusion/exclusion criteria. The themes generated included communication issues, information giving and decision-making. The literature suggests that communication and decision-making within cancer care are often mediated through support workers or family carers with minimal involvement of the person with intellectual disabilities. Information-giving by health professionals and support workers to people with intellectual disabilities was limited. This was often justified by the perceived distress this may cause.

Conclusion: Training for health professionals and support workers in supporting people with intellectual difficulties is required for more effective communication in cancer care.
\end{abstract}

Key words: Cancer, intellectual disabilities, narrative review 
Author copy: G Witham \& C Haigh Accepted 11/07/18 in European Journal of Oncology Nursing

\section{Introduction}

There is evidence that within the United Kingdom (UK) patients with cancer and a chronic condition or disability (including, for example, deafness/hearing impairment, blindness/partially sighted, intellectual disability and mental health conditions) are less likely to perceive their cancer care as "excellent" or "very good" (Bone et al 2014). The variation remains even after taking account of clinical factors such as cancer type, duration of treatment and hospital level factors. Bone et al (2014) suggest that this is related to clear differences in experiences among these groups. Miller et al (2014) highlight that, from a health professional perspective, discrimination and bias are a perceived disparity in cancer care. They also report better outcomes for those patients with well-established social support. Those patients with intellectual disabilities (ID) may have limited social networks making care provision more challenging (Sinding 2004). There are increasing numbers of people with ID and cancer, in part, due to increased longevity (for example, within England an increase by $53 \%$ of those $>50$ years age range between 2001-2021) (Emerson and Hatton 2008). There are a number of organisational barriers for people with ID in accessing healthcare services. These include limited service provision as well as physical barriers (Emerson 2011). There are also barriers related to health literacy and communication challenges for people with ID (Michael 2008). This has resulted in individuals with ID being excluded from General Practitioner (GP) consultations (Ward et al 2010, Wullink et al 2009). There are also issues of diagnostic overshadowing (Jopp \& Keys 2001). Diagnostic overshadowing occurs when symptoms related to physical health are mistakenly misinterpreted as behaviours typically associated with a diagnosis of intellectual impairment (Ovellette-Kuntz 2005). Attitudes of staff were also instrumental in the health care experience of people with ID (Alborz et al 2003, 2005, Ali et al 2013). There is evidence that doctors do not understand the health needs of people with ID (Ward et al 2010) and this has contributed to diagnostic overshadowing (Webber et al 2010, Dinsmore 2012). Although people with ID attend their GP at similar levels to the general population their health is less likely to be monitored (Emerson et al 2011) and this includes receiving health promotion and screening services (Broughton and Thomson 2000). Given the high degree of health problems with people with ID (Emerson and Baines 2010) and in comparison to GP consultation rates for other groups of patients who also have chronic conditions, people 
Author copy: G Witham \& C Haigh Accepted 11/07/18 in European Journal of Oncology Nursing

with ID have lower attendance rates (Felce et al 2008). There have also been studies highlighting the lack of support for patients with ID in general hospitals, including poor communication strategies by health professionals (Gibbs et al 2010). People with ID who also have cancer are often not told of both their diagnosis and prognosis, nor referred for specialist palliative care or given adequate pain relief (Tuffrey-Wijne et al 2007, Bernal and Tuffrey-Wijne 2008). The aim of this literature review is to explore the experiences of cancer care in relation to people with ID receiving cancer treatment. We have chronicled the research evidence within this area highlighting both issues that are pertinent to clinical practice and gaps in the evidence base with suggestions of future research.

\section{Methods}

We used a narrative approach producing an interpretive review, involving "the selection, chronicling and ordering of evidence to produce an account of the evidence" (Dixon-Woods et al 2005; 47). This approach was taken due to the quality, scarcity and diversity of the literature retrieved with less emphasis on evaluation criteria and methodological matters than other forms of review (May et al. 2005).

\section{Search Strategy}

We undertook a search for articles in English from the databases and search terms described in Table 1. We searched from (Jan) 2000-(March) 2018 to capture the limited range of papers within this subject area. Reference lists of relevant articles were also searched to identify related studies. The database searches and hand searches were undertaken following the PRISMA guidelines (Moher et al. 2009). After title and abstract review and the removal of duplicates and non-research papers, the remaining full-text papers were retrieved and scrutinised $(n=49)$. The application of the inclusion criteria further limited the number of papers to 10 (Figure 1).

(Insert Table 1) 
Author copy: G Witham \& C Haigh Accepted 11/07/18 in European Journal of Oncology Nursing

Inclusion \& exclusion criteria

Inclusion criteria were that papers were empirical, peer-reviewed, focussed on aspects of the treatment cancer journey for patients with ID and their formal or informal carers.

Papers were from 2000-2018 and in English. Exclusion criteria related to papers predominately reporting on cancer prevention or detection, risk/prevalence studies (prediagnosis), palliative care focused or review papers.

Quality appraisal

Studies were assessed for quality using the screening tool developed by Hawker et al (2002) with both authors independently rating the papers. This checklist appraises data on abstract and title, introduction and aims, methods and data, sampling, data analysis, ethics and bias, results, transferability or generalisability, implications and usefulness. Scores range from 9 (very poor) to 36 (good) and indicate the methodological rigour for each paper (see Table 2). As each paper was assessed by two researchers, a mean score for each paper was calculated. Studies were not excluded on the basis of the quality appraisal but rather this process illustrates the methodological strengths and weaknesses of each study included.

\section{Data synthesis}

The papers were analysed thematically to systematically search for commonalities and themes to describe the data (Braun and Clarke 2006). The first author reviewed each paper and data was coded to describe the study findings. Similar codes were grouped together into categories or themes to explore the relationships between and within studies. New categories were developed or modified as analysis continued and a coherent and detailed synthesis emerged.

(Insert Figure 1) 
Author copy: G Witham \& C Haigh Accepted 11/07/18 in European Journal of Oncology Nursing

\section{Results}

After application of the inclusion/exclusion criteria 10 papers were included in this review (Table 2). All the papers (except for Flynn et al 2015 and Sullivan \& Hussain 2008) were qualitative in design, from focus groups (Witham et al 2014) to participant observation (Jones et al 2006, Tuffrey-Wijne et al 2009, Tuffrey-Wijne et al 2010), case study, narrative life story approaches (Martean et al 2013, Tuffrey-Wijne \& Davies 2007, Cresswell \& TuffreyWijne 2008) and interviews (Flynn et al 2016). Flynn et al (2015) used questionnaires based on vignettes to explore stigma and to assess attitudes and care perceptions of UK oncology nurses, whilst Sullivan \& Hussain (2008) analysed hospital data sets to establish hospital admission for cancer and co-morbidity for people with ID.

(Insert Table 2)

Communication challenges

Communication issues were a common theme throughout the papers. Complex communication challenges were often exacerbated by the dependence of people with ID on others (Tuffrey-Wijne et al 2009, Martean et al 2013 Flynn et al 2016). Triadic relationships between carers or support workers, health professionals and the person with ID meant effective communication was predicated on all parties being able to articulate the issues and concerns in an inclusive and understandable way. This was within the context of complex decision-making about appropriate cancer treatment, issues of quality of life and potential side effects in addition to prognostic judgements related to outcomes (TuffreyWijne and Davies 2006, Jones et al 2006, Creswell and Tuffrey-Wijne 2008, Tuffrey-Wijne et al 2009, Witham et al 2014). Martean et al (2013), for example, suggest that carers and families of people with ID, who present with psychological distress may encourage happiness or "forced jolliness" (Tuffrey-Wijne et al 2010; 228) and minimise the concerns of the person with ID. Martean et al (2013) refer to the 'handicapped smile' (Sinason 1992) where people with ID learn to mask distress from others and conform to the cultural requirement to be positive. In terms of information giving by support workers to the person with ID, Tuffrey-Wijne et al (2009) suggest that it was based on what the support worker would want themselves. This was coupled with a lack of confidence from the support 
Author copy: G Witham \& C Haigh Accepted 11/07/18 in European Journal of Oncology Nursing

worker in their ability to explore the issues in a meaningful way and a desire to protect the person with ID and cancer from distress. Tuffrey-Wijne et al (2009) further suggest that health professionals often disregarded or misinterpreted their interactions with someone with ID. They had a limited awareness of the tendency for people with ID to acquiesce. This led to assumptions about a person's comprehension and ability to understand cancer treatment (Tuffrey-Wijne et al 2009, 2010, Martean et al 2013, Flynn et al 2016).

Communication by health professionals to the person with ID was limited with most discussion on cancer treatment and care issues mediated through support workers or family irrespective of severity of the ID (Martean et al 2013, Flynn et al 2015, 2016). Flynn et al (2015), for example, indicate from their sample of oncology nurses that none of the participants reported that they would consult the patient themselves about how best to support them. Some studies also report the exclusion of support workers and carers from care decisions (Jones et al 2006, Witham et al 2014) with Creswell and Tuffrey-Wijne (2008) giving the example of carers not being informed of a hospital transfer leaving the person with ID isolated and alone.

Information needs

Information needs surrounding symptoms and side effects of treatment were often unmet (Tuffrey-Wijne and Davies 2006, Jones et al 2006, Creswell and Tuffrey-Wijne 2008). There was a lack of disclosure related to diagnosis and prognosis (Tuffrey-Wijne and Davies 2006, Creswell and Tuffrey-Wijne 2008, Martean et al 2013, Flynn et al 2016). Flynn et al (2016) highlights that family caregivers were particularly concerned at avoiding cancer information that they perceived as psychologically distressing for their relative. For health professionals there appeared a lack of knowledge about supporting people with ID and cancer (Jones et al 2006, Tuffrey-Wijne et al 2009, 2010, Witham et al 2014, Flynn et al 2015, 2016). Flynn et al (2015), for example, examined the attitudes and care perceptions of UK oncology nurses using a questionnaire with vignettes to explore stigma. They had a sample size of 83 and the results indicated that, in terms of care perceptions, participants felt more confident in their knowledge, training and experience and better able to identify and meet the needs and communicate with patients without an ID. Patients with an ID were perceived as more stressful and challenging to support and care for. They can be perceived as a burden and 
Author copy: G Witham \& C Haigh Accepted 11/07/18 in European Journal of Oncology Nursing

could cause "trouble" (Martean et al 2013: 287). The interactional effects suggested that previous experience by participants of working with people with ID generated more positive interactions and confidence when providing care. This experience further suggested less stress and the ability to provide appropriate support in comparison to those participants with no previous experience. Jones et al (2006) examined the experiences of support workers in meeting the cancer information needs of people with ID. Using thematic analysis, the findings suggest the high burden and challenge of often young support workers in confronting their own issues of bereavement and loss in supporting someone with advanced cancer. The expectations of support workers were generally high, however, understanding cancer information and its impact and effectively translating that to the person with ID was something many felt ill equipped to do. This is particularly important because of the tendency of health professionals to mediate information via support workers (Tuffrey-Wijne et al 2009, Martean et al 2013, Flynn et al 2015, 2016).

Decision-making

Decision-making was one of the key themes from most of the papers with the person with ID often excluded from the decision-making process (Jones et al 2006, Tuffrey-Wijne et al 2009 , Flynn et al 2015,2016$)$. There are a number of reasons for this. Paternalism appeared to be an issue with carers and support workers particularly not wanting to involve people with ID in cancer care decisions if it was perceived to be distressing (Jones et al 2006, Tuffrey-Wijne et al 2009, Flynn et al 2016). Tuffrey-Wijne et al (2010) suggest best interest decisions may be suitable for someone with profound ID who cannot make an informed choice. It was, however, distressing for people with ID who could be supported to make decisions and understand but were not allowed to do so because they were given in adequate information and little or no opportunity to be heard. Issues of non-disclosure related to diagnosis and prognosis meant that person with ID could clearly not make informed decisions. Tuffrey-Wijne et al (2009) highlight these issues with five participants from their sample not having treatment on either the insistence of carers or an assumption by doctors that they would not cope. Truth telling was arbitrary and often dependent on the support workers personal preferences rather than an assessment of the person's wishes. For people with mild to moderate ID the implications of cancer were difficult to assimilate, 
Author copy: G Witham \& C Haigh Accepted 11/07/18 in European Journal of Oncology Nursing

with often conflicting or minimal information provided by health professionals. Effective communication by health professionals could open up choice and aid decision-making (Martean et al 2013).

Witham et al (2014) explored health professionals experience of vulnerable groups undergoing chemotherapy within a tertiary oncology centre, and one group identified was people with ID. Participants indicated that trying to assess understanding in relation to informed consent for treatment decision-making was difficult and exacerbated by the perception of an increased patient volume. Creating the time and the environment to assess whether the information had been retained and understood was challenging and adapting treatment pathways to meet the social and psychological needs of people with ID was timeconsuming, requiring complex interdepartmental and inter-professional co-ordination. For example, issues like face masks to keep the head in position for head and neck radiotherapy and the claustrophobic nature of CT or MR scans can be challenging and require reasonable adjustments to support patients with ID. Whilst health professional attitudes have an impact on cancer care for people with ID (Creswell and Tuffrey-Wijne 2008, Martean et al 2013, Flynn et al 2016) there is little published data exploring some of the environmental and logistical challenges of navigating cancer treatment.

Sullivan \& Hussain (2008) examined the records of 9409 people in Australia linked with the Hospital Morbidity Data System after previously identifying people with ID linked with the Western Australian Cancer Registry. The data tentatively suggest that co-morbidities remain high within this group with incomplete data sets suggesting this to be an underestimation of the scale and extent. People with ID were no less likely to be diagnosed with cancer than the general population but significant morbidity may be a feature and experience of cancer treatment and indeed could influence whether treatment was initiated in the first place. This contextual issue may influence the decision-making process. It has implications for support for both the person with ID and support workers, and highlights some of the complexity in managing cancer treatment within this patient group. 
Author copy: G Witham \& C Haigh Accepted 11/07/18 in European Journal of Oncology Nursing

\section{Discussion}

There appears a paucity of evidence published over the last 18 years related to cancer treatment issues of patients with ID. Of the limited papers available it is of note that 4 of the 10 papers are co-written by the same researcher (Tuffrey-Wijne) and appear to be reporting on the same study. In terms of the evaluation of the studies (Table 2), the quality indicators (Hawker et al 2002) were 16-32 with $50 \%$ of the papers $30-32,36$ being the maximum score indicating the study is good. There was limited methodological diversity with 8 studies of qualitative design with 9 conducted in the United Kingdom (UK). People with ID and cancer remain a small, vulnerable population and therefore may represent a difficult group to access and research (Witham et al 2015). Poor communication was also identified in conveying issues involving decision making, particularly between the person with ID and health professionals but also in conveying sensitive and complex information to support workers (Tuffrey-Wijne et al 2009, 2010). There is a need for more systematic training and support to meet the often complex co-morbidities of this group within the context of cancer care (Flynn et al 2015, 2016).

There is some limited evidence that treatment pathways are rarely adapted to the complex needs within this population (Witham et al 2014). Addressing the needs of support workers is important since they may be the central figure in interpreting the, often multi-faceted, decision-making processes and treatment regimens associated with cancer therapies (Sullivan and Hussain 2008). Paternalistic attitudes appear to be a feature of the experience of people with ID with limited involvement within the decision-making process (Flynn et al 2016). This exclusion of people with ID in health consultations is reflected in the wider literature, (Ward et al 2010, Wullink et al 2009, Ali et al 2013). They experience limited screening, health reviews and investigations. Decisions are often made for them (Ferguson et al 2010). Nind and Seale (2009) identify that barriers to access are often unintended, multiple and embedded. Unintended issues refer to the potential consequences of "kindness" and over-support in making decisions for people with ID without facilitating adequate strategies to include them. These findings appear relevant within this narrative review (Flynn et al 2015, 2016, Tuffrey-Wijne et al 2009). There are multiple barriers to accessing cancer treatment for this group. For example, if someone requires radiotherapy 
Author copy: G Witham \& C Haigh Accepted 11/07/18 in European Journal of Oncology Nursing

then they may need daily transport, this may require effective time management to be ready on time when the transport arrives. There remains limited exploration of these barriers to accessing cancer treatment within this review. For example, 3 papers present single case studies (Tuffrey-Wijne and Davies 2007, Cresswell and Tuffrey-Wijne 2008, Martean et al 2013) and whilst this may offer rich data it remains unfocused. It does not directly explore or address cancer treatment barriers in people with ID. Standard procedure for radiotherapy is to lie still on a couch for consecutive days lasting for potentially weeks (Verhey 1995). This can be potentially stressful for people with ID. The necessity to remain alone in a room during the procedure with automated instructions may generate anxiety for patients with ID. Both Witham et al (2014) and Flynn et al (2015) acknowledge the challenges for people with ID in successfully navigating treatment pathways. This remains an under-researched area within the published literature and requires more empirical work examining the cancer journey and how it impacts on people with ID. There may also be embedded barriers that relate to promoting healthy lifestyles, for example, providing information about health promotion in a format that people with ID would understand (Hanna et al 2010).

Decision-making has been highlighted as a theme within this literature review. Lotan and Ells (2010) have highlighted some practical considerations in relation to decision-making and ID. These include including understanding personal characteristics such as intellectual profile and adaptive skills, the person's preferences and establishing consensus among staff about realistic options available to the person. The decision-making process should also involve preparing conversations with the person with ID. This should include the format for the discussions with a plan to reinforce any expression of independent ideas whilst sometimes having to acknowledge possible unrealistic expectations or limitations in the person's understanding that negate meaningful decision-making. Lotan and Ells (2010) further suggest that preparing for a consultation involving decision-making requires attentiveness to the needs of the person with ID and how to support them during the meeting. It also requires preparation of other attendees and adequate follow up to review the conversations, process, decisions and care plan.

Staff training was highlighted by Flynn et al $(2015,2016)$, Jones et al $(2006)$ and this relates to both health care professionals and support workers. This is reflected in the wider 
Author copy: G Witham \& C Haigh Accepted 11/07/18 in European Journal of Oncology Nursing

literature (Hemm et al 2015, Sowney and Barr 2006, Cartlidge and Read 2010) with issues related to ensuring fully informed consent, general communication, specific knowledge and information and specific training based on the speciality of the health staff (Hemm et al 2015). This specialist training, however, can be seen to extend beyond health staff with both Sullivan and Hussain (2008) and Jones et al (2006) suggesting that support workers of people with ID need further information and specific support in conveying complex cancer treatments. There was no exploration of the specific nature of such training within the included papers. Further research could explore the nature and type of training required. There was only one paper (Flynn et al 2016) that specifically examined a subset of 4 family carer experiences in supporting someone with ID and cancer.

In synthesising some of the recommendations generated from this review, Table 3 highlights how health and social care professionals can support people with ID whilst having cancer treatment.

(Insert Table 3)

Study evaluation and future research

This narrative review has some limitations, there were a small number of studies (10) and therefore there is a risk of publication bias and narrative reviews may encounter a greater risk of confirmation bias (Baumeister \& Leary 1997). We could have included unpublished and grey literature to attempt to examine the issues more widely but there are ongoing issues of low quality and low accessibility (Corlett 2011). We therefore only presented peerreviewed evidence to highlight and map this current landscape. There is a dearth of evidence on cancer treatment issues in people with ID with no body of evidence that specifically identifies effective interventions, responses, or models of best practice. Therefore, research that identifies models of good practice in working with people with ID and cancer is needed. There is a lack of data from countries outside of the UK. Comparative studies would be particularly beneficial to our understanding of the issues and health and social care responses within different cultural contexts. In terms of methodological inquiry, more quantitative approaches are needed to provide larger scale data on the experiences and needs of particular populations involved in service provision, for example, oncology nurses, medical staff, radiographers. Further research is also needed in terms of how 
healthcare responses affect people with experience of both ID and cancer. Qualitative inquiry is required to establish the needs of family and friends of people with ID and cancer and should extend to patients' voices of the treatment challenges they encounter.

\section{Conclusion}

This narrative review aimed to examine the cancer treatment experiences related to people with ID and highlighted the dearth of published evidence available. Effective communication is central to supporting people with ID but this remains challenging. Complex comorbidities can require contact with a wider social network of supporters including, carers (paid and unpaid), relatives and specialist health teams. The decision-making process is complex as is the ability to convey specialist information about cancer treatment/side effects in a way patient and support worker can understand. This has implications for both patient safety and risk as well as compliance with treatment. Cancer therapies can be lengthy and complex and involve procedures that are particularly stressful to people with ID. Radiotherapy, chemotherapy regimens and diagnostic scanning can all require a level of co-operation and adaptation that can be challenging in meeting the needs of this population group. Further research needs to focus on these areas and to the wider context and environment of care within oncology settings. This would begin to offer avenues to provide services that can adapt to the complex requirements of people with ID and cancer. 
Author copy: G Witham \& C Haigh Accepted 11/07/18 in European Journal of Oncology Nursing

\section{References}

Alborz A, McNally R, Swallow A. From the Cradle to the Grave: a literature review of access to health care for people with learning disabilities across the lifespan (2003) National Coordinating Centre for NHS Service Delivery and Organisation, London.

Alborz A, McNally R, Glendinning C. (2005) Access to health care for people with learning disabilities in the UK: mapping the issues and reviewing the evidence. Journal of Health Services Research \& Policy 2005;10:173-82. 127.

Ali A, Scior K, Ratti V, Strydom A, King M, Hassiotis A (2013) Discrimination and other Barriers to Accessing Health Care: Perspectives of Patients with Mild to Moderate Intellectual Disability and Their carers, PLoS ONE 8(8): e70855. doi:10.1371/journal.pone.0070855

Baumeister R and Leary M (1997). Writing narrative literature reviews. Review of General Psychology, 1(3) 311-320.

Bernal J and Tuffrey-Wijne I (2008) Telling the truth-or not: Disclosure and information for people with intellectual disabilities who have cancer. International Journal on Disability and Human Development 7:365-70.

Bone A, Mc Grath-Lone L, Day S, Ward H (2014) Inequalities in the care experiences of patients with cancer: analysis of data from the National Cancer Patient Experience Survey 2011-2012, BMJ Open 4:e004567. Doi:10.1136/bmjopen-2013-004567

Braun V and Clarke V (2006) Using thematic analysis in Psychology. Qualitative research in Psychology, 3(2) 77-101.

Broughton S \& Thomson K (2000) Women with learning disabilities: risk behaviours and experiences of the cervical smear test. Journal of Advanced Nursing 32: 905-912.

Cartlidge D and Read S (2010) Exploring the needs of hospice staff supporting people with an intellectual disability: a UK perspective. International Journal of Palliative Nursing, 16, 9398.

Corlett R T (2011) Trouble with Grey Literature. Biotropica, 43(1) 3-5. 
Author copy: G Witham \& C Haigh Accepted 11/07/18 in European Journal of Oncology Nursing

Cresswell A and Tuffrey-Wijne I (2008) The come back kid; I had cancer but I got through it, British Journal of Learning Disabilities 36 152-156.

Dagnan D. \& Waring M. (2004) Linking stigma to psychological distress: testing a socialcognitive model of the experience of people with intellectual disabilities. Clinical Psychology and Psychotherapy 11, 247-254.

Dinsmore AP (2012) A small-scale investigation of hospital experiences among people with a learning disability on Merseyside: speaking with patients and their carers. British Journal of Learning Disabilities 40: 201-212.

Dixon-Woods M, Agarwal S, Jones D, Young B, Sutton A (2005) Synthesising qualitative and quantitative evidence: a review of possible methods. Journal of Health Services Research \& Policy, 10: 45-53.

Emerson E. \& Hatton S (2008) People with Learning disability in England. Centre of Disability Research, http://eprints.lancs.ac.uk/9515/1/CeDR 2008-

1 People with Learning Disabilities in England.pdf (accessed 03/07/18)

Emerson E., Baines S., Allerton L. \& Welch V. (2011) Health Inequalities and People With Learning Disabilities in the UK. I. H. a. L. L. D. D. Observatory, Public Health England, London. Emerson E. (2011) Health status and health risks of the "hidden majority" of adults with intellectual disability. Intellectual and Developmental Disabilities 49, 155-165.

Felce D, Baxter H, Lowe K, Dunstan F, Houston H, Jones G, et al. The Impact of Checking the Health of Adults with Intellectual Disabilities on Primary Care Consultation Rates, Health Promotion and Contact with Specialists. Journal of Applied Research in Intellectual Disabilities 2008;21:597-602.

Flynn S, Hulbert-Williams, Bramwell R, Stevens-Gill D, Hulbert-Williams N (2015) Caring for cancer patients with an intellectual disability: Attitudes and care perceptions of UK oncology nurses European Journal of Oncology Nursing, 19: 568-574.

Flynn S, Hulbert-Williams NJ, Hulbert-Williams L, Bramwell R (2016) “You don't know what's wrong with you": an exploration of cancer-related experiences in people with an intellectual disability, Psycho-Oncology, 25: 1198-1205. 
Author copy: G Witham \& C Haigh Accepted 11/07/18 in European Journal of Oncology Nursing

Gibbs SM, Brown MJ, Muir WJ (2008) The experiences of adults with intellectual disabilities and their carers in general hospitals: a focus group study. Journal of intellectual disability Research, 2008 52: 1061-1077.

Hanna LM, Taggart L, Cousins W (2010) Cancer prevention and health promotion for people with intellectual disabilities: an exploratory study of staff knowledge. Journal of Intellectual Disabilities Research, 55(3) PP 281-291.

Hawker S, Payne S, Kerr C, Hardey M, Powell J (2002) Appraising the Evidence: Reviewing Disparate Data Systematically. Qualitative Health Research, 12 (9) 1284-1299.

Hemm C, Dagnan D, Meyer TD (2015) Identifying training needs for mainstream healthcare professionals, to prepare them for working with individuals with Intellectual disabilities: a Systematic Review. Journal of Applied Research in Intellectual Disabilities, 28, 98-110.

Jones A, Tuffrey-Wijne I, Bernal J, Butler G, Hollins S (2006) Meeting the cancer information needs of people with learning disabilities: experiences of paid carers, British Journal of learning disabilities, 35, 12-18.

Jopp DA \& Keys CB (2001) Diagnostic overshadowing reviewed and reconsidered. American Journal of Mental Retardation, 106: 416-433.

Lotan G and Ells C (2010) Adults with Intellectual and developmental disabilities and participation in decision-making: ethical considerations for professional-client practice. Intellectual and Developmental Disabilities, 48 92) 112-125.

May J, Pope C \& Popay J (2005) Systematically reviewing qualitative and quantitative evidence to inform management and policy making in the health field. Journal of Health Sciences Research Policy 10 (Suppl 1), 6-20.

Martean MH, Dallos R, Stedmon J, Moss D (2013) Jo's Story: the journey of one woman's experience of having cancer and a 'learning disability', British Journal of Learning Disabilities $42,282-291$. 
Author copy: G Witham \& C Haigh Accepted 11/07/18 in European Journal of Oncology Nursing

Michael J (2008) Healthcare for All: Report of the Independent Inquiry into Access to Healthcare for People with Learning Disabilities: Independent Inquiry into Access to Healthcare for People with Learning Disabilities, London.

Miller PA, Sinding C, McGillicuddy P, Gould J, Fitzpatrick-Lewis D, Learn L, Wiernikowski J, Fitch M I (2014) Disparities in cancer care: Perspectives from the front line, Palliative and Supportive Care 12, 175-181.

Moher D, Liberati A, Tetzlaff J \& Altman D G for the PRISMA Group (2009) Preferred reporting items for systematic reviews and meta-analyses: the PRISMA statement. British Medical Journal 339, 332-336.

Nind M and Seale J (2009) Concepts of access for people with learning difficulties: towards a shared understanding. Disability \& Society, 24(3) 273-287.

Ovellette-Kuntz H (2005) Understanding health Disparities and inequities faced by individuals with intellectual disabilities. Journal of Applied Research in Intellectual Disabilities, 18; 113-121.

Sinding C (2004) Informal care-Two-tiered care? The work of family members and friends in hospitals and cancer centres, Journal of Sociology and Social Welfare, 31, 69-86.

Sinason V (1992) Mental Handicap and the Human Condition: New Approaches from the Tavistock. Free Association Books, London.

Sowney M and Barr O (2006) Caring for adults with intellectual disabilities: perceived challenges for nurses in accident and emergency units. Journal of Advanced Nursing, 55, 3645.

Sullivan SG and Hussain R (2008) Hospitalisation for cancer and co-morbidities among people with learning disability in Australia, British Journal of Learning Disabilities, 36, 191197.

Tuffrey-Wijne and Davies J (2007) This is my story: I've got cancer 'The Veronica Project': an ethnographic study of the experiences of people with learning disabilities who have cancer, British Journal of learning Disabilities, 35, 7-11. 
Author copy: G Witham \& C Haigh Accepted 11/07/18 in European Journal of Oncology Nursing

Tuffrey-Wijne, Bernal J, Hubert J, Butler G, Hollins S (2009) People with learning disabilities who have cancer: an ethnographic Study, British Journal of General Practice, 59: 503-509.

Tuffrey-Wijne I, Bernal J, Hollins S (2010) Disclosure and understanding of cancer diagnosis and prognosis for people with intellectual disabilities: Findings from an ethnographic study, European Journal of Oncology Nursing, 14: 224-230.

Verhey L J (1995) Immobilising and positioning patients for Radiotherapy. Seminars in Radiation Oncology 5(2) 100-114.

Ward RL, Nichols AD, Freedman RI (2010) Uncovering health Care inequalities among adults with intellectual and developmental disabilities, Health Social Work. 35: 280-290.

Webber R, Bowers B, Bigby C (2010) Hospital experiences of older people with intellectual disability: Responses of group home staff and family members. Journal of Intellectual Development Disability 35: 155-164.

Witham G, Haigh C, Foy S (2014) The Challenges of Health Professionals in meeting the needs of vulnerable patients undergoing chemotherapy: A focus group study, Journal of Clinical Nursing 23, 19-20, 2844-2853.

Witham G, Beddow A, Haigh C (2015) Reflections on access: too vulnerable to research? Journal of Research in Nursing, 20(1) 28-37.

Wullink M, Veldhuijzen W, Lantman- de Valk HMJ, Metsemakers JFM, Dinant G-J (2009) Doctor-patient communication with people with intellectual disability- a qualitative study. BMC Family Practice 10: 82. 
Author copy: G Witham \& C Haigh Accepted 11/07/18 in European Journal of Oncology Nursing

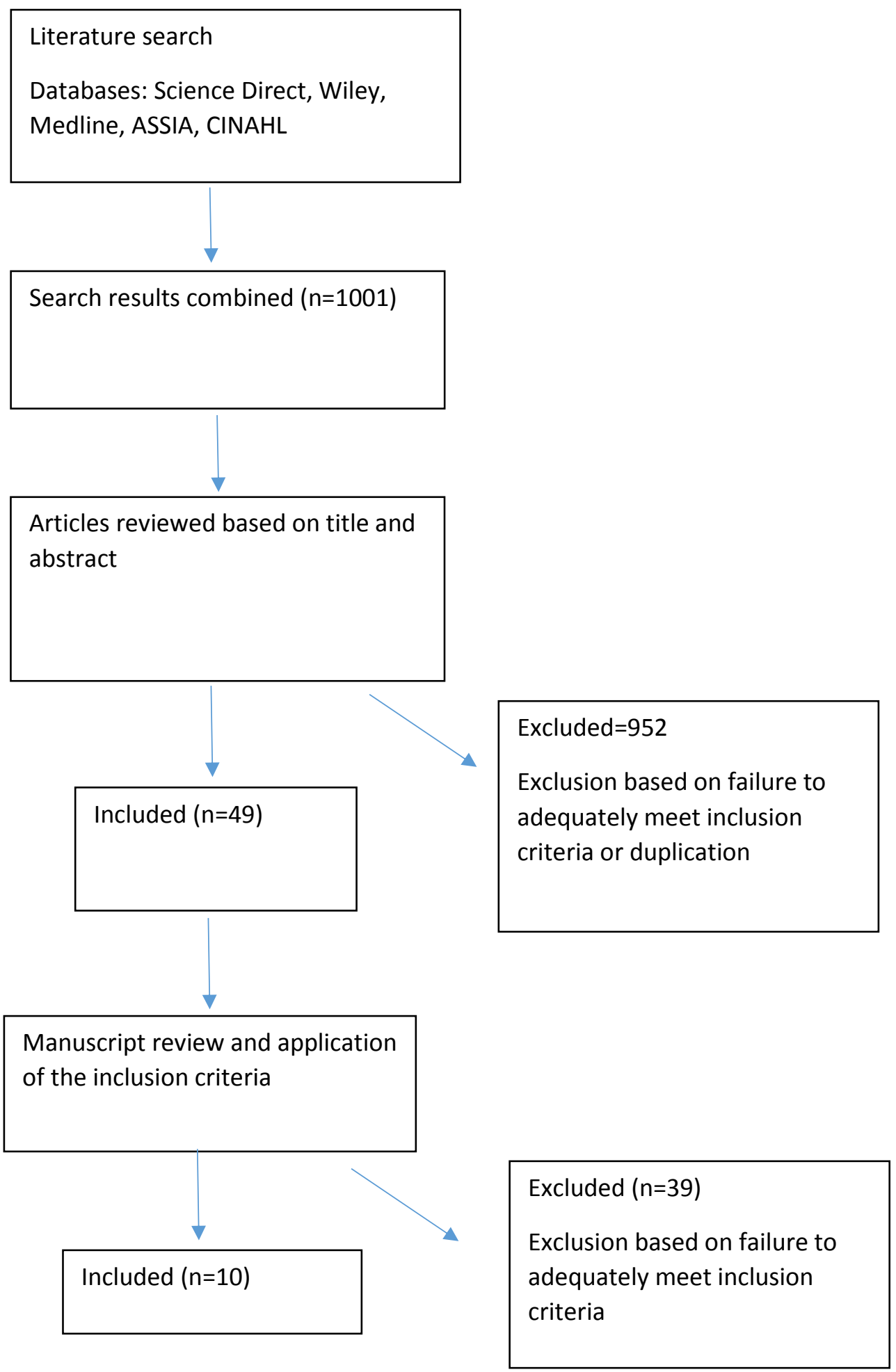

Figure $1:$ Flow diagram of the literature review process 
Author copy: G Witham \& C Haigh Accepted 11/07/18 in European Journal of Oncology Nursing

Table 1: Search terms

Databases searched: MEDLINE (Web of Knowledge), CINAHL, SCIENCE DIRECT, ASSIA

(ProQuest), WILEY

Search terms:

Cancer AND "learning disabili*”

Cancer AND “intellectual disabilit*”

Cancer AND "intellectual disabilit*" AND carer*

Cancer AND "learning disabilit*" AND carer*

Cancer AND "learning disabilit* AND famil*

Cancer AND "intellectual disabilit*" AND famil* 
Table 2: Included papers

\begin{tabular}{|c|c|c|c|c|c|}
\hline Authors & Title & $\begin{array}{l}\text { Methodology/ } \\
\text { method }\end{array}$ & Participants & Country & Quality indicator \\
\hline $\begin{array}{l}\text { Jones et } \\
\text { al (2006) }\end{array}$ & $\begin{array}{l}\text { Meeting } \\
\text { the cancer } \\
\text { information } \\
\text { needs of } \\
\text { people with } \\
\text { learning } \\
\text { disabilities: } \\
\text { experiences } \\
\text { of paid } \\
\text { carers }\end{array}$ & $\begin{array}{l}\text { Participant } \\
\text { observation of } \\
\text { using a booklet } \\
\text { "getting on with } \\
\text { cancer" and then } \\
\text { separate } \\
\text { interview with } \\
\text { supporter and } \\
\text { person with } \\
\text { learning } \\
\text { difficulties }\end{array}$ & $\begin{array}{l}5 \text { participants with } \\
\text { learning difficulties } \\
\text { and their } \\
\text { supporters }\end{array}$ & $\begin{array}{l}\text { United } \\
\text { Kingdom }\end{array}$ & 29 \\
\hline $\begin{array}{l}\text { Tuffrey- } \\
\text { Wijne I } \\
\text { and } \\
\text { Davies J } \\
\text { (2007) }\end{array}$ & $\begin{array}{l}\text { This is my } \\
\text { story: I've } \\
\text { got cancer } \\
\text { 'The } \\
\text { Veronica } \\
\text { Project': an } \\
\text { ethnograph } \\
\text { ic study of } \\
\text { the } \\
\text { experiences } \\
\text { of people } \\
\text { with } \\
\text { learning } \\
\text { disabilities } \\
\text { who have } \\
\text { cancer }\end{array}$ & $\begin{array}{l}\text { Single case study } \\
\text { using Thematic } \\
\text { field analysis }\end{array}$ & $\begin{array}{l}1 \text { participant with } \\
\text { learning difficulties }\end{array}$ & $\begin{array}{l}\text { United } \\
\text { Kingdom }\end{array}$ & 19 \\
\hline
\end{tabular}




\begin{tabular}{|c|c|c|c|c|c|}
\hline $\begin{array}{l}\text { Tuffrey-Wijne } \\
\text { I, Bernal J, } \\
\text { Hubert J, } \\
\text { Butler G, } \\
\text { Hollins S } \\
\text { (2009) }\end{array}$ & $\begin{array}{l}\text { People with } \\
\text { learning } \\
\text { disabilities } \\
\text { who have } \\
\text { cancer: an } \\
\text { ethnographic } \\
\text { Study }\end{array}$ & $\begin{array}{l}\text { Ethnographic } \\
\text { study using } \\
\text { participant } \\
\text { observation } \\
\text { (over } 250 \\
\text { hours in } 7 \\
\text { months) } \\
\text { following } \\
\text { grounded } \\
\text { theory } \\
\text { principles }\end{array}$ & $\begin{array}{l}13 \\
\text { participants } \\
\text { with mild to } \\
\text { moderate } \\
\text { learning } \\
\text { difficulties }\end{array}$ & $\begin{array}{l}\text { United } \\
\text { Kingdom }\end{array}$ & 27 \\
\hline $\begin{array}{l}\text { Tuffrey-Wijne } \\
\text { I, Bernal J, } \\
\text { Hollins S } \\
\text { (2010) }\end{array}$ & $\begin{array}{l}\text { Disclosure } \\
\text { and } \\
\text { understandin } \\
\text { g of cancer } \\
\text { diagnosis and } \\
\text { prognosis for } \\
\text { people with } \\
\text { intellectual } \\
\text { disabilities: } \\
\text { Findings from } \\
\text { an } \\
\text { ethnographic } \\
\text { study }\end{array}$ & $\begin{array}{l}\text { Ethnographic } \\
\text { study using } \\
\text { participant } \\
\text { observation }\end{array}$ & $\begin{array}{l}13 \\
\text { participants } \\
\text { with mild to } \\
\text { moderate } \\
\text { learning } \\
\text { difficulties }\end{array}$ & $\begin{array}{l}\text { United } \\
\text { Kingdom }\end{array}$ & 32 \\
\hline $\begin{array}{l}\text { Cresswell A } \\
\text { and Tuffrey- } \\
\text { Wijne I (2008) }\end{array}$ & $\begin{array}{l}\text { The come } \\
\text { back kid; I had } \\
\text { cancer but I } \\
\text { got through it }\end{array}$ & $\begin{array}{l}\text { Single } \\
\text { descriptive } \\
\text { case study }\end{array}$ & $\begin{array}{l}1 \text { participant } \\
\text { with learning } \\
\text { difficulties }\end{array}$ & $\begin{array}{l}\text { United } \\
\text { Kingdom }\end{array}$ & 16 \\
\hline $\begin{array}{l}\text { Sullivan SG } \\
\text { and Hussain R } \\
(2008)\end{array}$ & $\begin{array}{l}\text { Hospitalisatio } \\
\mathrm{n} \text { for cancer } \\
\text { and co- } \\
\text { morbidities } \\
\text { among people } \\
\text { with learning } \\
\text { disability in } \\
\text { Australia }\end{array}$ & $\begin{array}{l}\text { Case review } \\
(\mathrm{n}=9409) \\
\text { from a cancer } \\
\text { registry }\end{array}$ & $\begin{array}{l}173 \text { had } \\
\text { learning } \\
\text { difficulties }\end{array}$ & Australia & 31 \\
\hline
\end{tabular}




\begin{tabular}{|c|c|c|c|c|c|}
\hline $\begin{array}{l}\text { Martean et al } \\
\text { (2013) }\end{array}$ & $\begin{array}{l}\text { Jo's Story: the } \\
\text { journey of } \\
\text { one woman's } \\
\text { experience of } \\
\text { having cancer } \\
\text { and a } \\
\text { 'learning } \\
\text { disability' }\end{array}$ & $\begin{array}{l}\text { Single case } \\
\text { study using } \\
\text { Thematic field } \\
\text { analysis }\end{array}$ & $\begin{array}{l}1 \text { participant } \\
\text { with learning } \\
\text { difficulties }\end{array}$ & $\begin{array}{l}\text { United } \\
\text { Kingdom }\end{array}$ & 25 \\
\hline $\begin{array}{l}\text { Witham et al } \\
\text { (2014) }\end{array}$ & $\begin{array}{l}\text { The } \\
\text { Challenges of } \\
\text { Health } \\
\text { Professionals } \\
\text { in meeting } \\
\text { the needs of } \\
\text { vulnerable } \\
\text { patients } \\
\text { undergoing } \\
\text { chemotherap } \\
\text { y: A focus } \\
\text { group study }\end{array}$ & $\begin{array}{l}2 \text { Focus } \\
\text { groups with } \\
\text { health } \\
\text { professionals } \\
\text { using a } \\
\text { narrative } \\
\text { approach }\end{array}$ & $\begin{array}{l}18 \\
\text { participants } \\
\text { ( } 9 \text { in each } \\
\text { focus group) }\end{array}$ & $\begin{array}{l}\text { United } \\
\text { Kingdom }\end{array}$ & 30 \\
\hline $\begin{array}{l}\text { Flynn et al } \\
\text { (2015) }\end{array}$ & $\begin{array}{l}\text { Caring for } \\
\text { cancer } \\
\text { patients with } \\
\text { an intellectual } \\
\text { disability: } \\
\text { Attitudes and } \\
\text { care } \\
\text { perceptions } \\
\text { of UK } \\
\text { oncology } \\
\text { nurses }\end{array}$ & $\begin{array}{l}\text { Used a } \\
\text { questionnaire } \\
\text { with vignettes } \\
\text { (to explore } \\
\text { stigma) }\end{array}$ & $\begin{array}{l}83 \text { oncology } \\
\text { nurses }\end{array}$ & $\begin{array}{l}\text { United } \\
\text { Kingdom }\end{array}$ & 30 \\
\hline $\begin{array}{l}\text { Flynn et al } \\
\text { (2016) }\end{array}$ & $\begin{array}{l}\text { "You don't } \\
\text { know what's } \\
\text { wrong with } \\
\text { you": an } \\
\text { exploration of } \\
\text { cancer- } \\
\text { related } \\
\text { experiences in } \\
\text { people with } \\
\text { an intellectual } \\
\text { disability }\end{array}$ & $\begin{array}{l}\text { Qualitative } \\
\text { Interviews }\end{array}$ & $\begin{array}{l}6 \text { people with } \\
\text { ID and } 12 \\
\text { participants } \\
\text { within their } \\
\text { supportive } \\
\text { network }\end{array}$ & $\begin{array}{l}\text { United } \\
\text { Kingdom }\end{array}$ & 30 \\
\hline
\end{tabular}


Table 3: Implications for practice.

Provide training for oncology nurses in supporting patients with ID.

Provide information for support workers and carers of people with ID in managing side effects of cancer treatment and training in discussing communication issues.

Health professionals need to explore the logistic problems of navigating cancer treatment for people with ID and examine how pathways can be adapted.

Designate adequate time and planning to consultations involving decision-making and involve supporters/carers who know the person with ID.

Establish the most effective way to convey information in an understandable way to the person with an ID and provide structured follow up consultations to discuss any subsequent concerns generated by either the person with ID or their support worker/carer. 